\title{
Stenotrophomonas africana sp. nov., an Opportunistic Human Pathogen in Africa
}

\author{
M. DRANCOURT,${ }^{1}$ C. BOLLET, ${ }^{2}$ AND D. RAOULT ${ }^{1 *}$ \\ Unité des Rickettsies CNRS EP J0054, Faculté de Médecine, ${ }^{1}$ and AFCOPAT, \\ Faculté de Pharmacie, ${ }^{2} 13385$ Marseille Cedex 05, France
}

\begin{abstract}
A gram-negative bacterium was isolated from a cerebrospinal fluid sample from an HIV-seropositive Rwandan refugee with primary meningoencephalitis. This Marseille-Goma sample $B$ isolate, strain MGB $^{\text {T }}$ ( $T=$ type strain), was found to exhibit evolutionary homology with Stenotrophomonas maltophilia, as determined by a 16S rRNA gene sequence analysis, and this finding was reflected by similar phenotypic traits. MGB $^{\mathrm{T}}$ could, however, be distinguished from the $S$. maltophilia type strain by using a number of biochemical and physiological tests, and a genotypic analysis of the two strains in which DNA homology was used revealed only $35 \%$ homology between them. Furthermore, the antibiotic susceptibility of MGB $^{\mathrm{T}}$ was restricted to netilmicin, ciprofloxacin, trimethoprim-sulfamethoxazole, and colimycin. On the basis of these results we propose that MGB $^{\mathrm{T}}$ is a representative of a new species in the genus Stenotrophomonas, Stenotrophomonas africana.
\end{abstract}

In August 1994, an outbreak of typhus was suspected among predominantly Rwandan refugees suffering from AIDS in Goma, Zaire, following the observation of cases of meningoencephalitis associated with bilateral conjunctivitis which led to death or were cured with chloramphenicol (1). Patients with the illness were found to be infested with body lice, and cerebrospinal fluid (CSF) samples were collected and were clear. However, a diagnosis of typhus was subsequently ruled out following examination of patients and serological testing. Furthermore, efforts to detect rickettsiae in body lice by molecular methods were unsuccessful. CSF samples were therefore studied further in order to identify the etiological agent of this outbreak. From one of these samples a highly resistant gramnegative bacterium was isolated. Polyphasic characterization methods demonstrated that this isolate was similar to, yet distinct from, Stenotrophomonas (Xanthomonas) maltophilia, a species known to cause hospital-acquired infections and recently implicated in opportunistic infections in HIV-infected patients (2).

\section{MATERIALS AND METHODS}

Bacterial strains. Stenotrophomonas maltophilia ATCC $13637^{\mathrm{T}}(\mathrm{T}=$ type strain) was obtained from the American Type Culture Collection, Rockville, Md. Isolate MGB $^{\mathrm{T}}$ (Marseille-Goma sample B) was obtained as described below.

Isolation, culturing, and phenotypic characterization of isolate MGB ${ }^{\mathrm{T}}$. CSF samples that were obtained by lumbar puncture of Rwandan refugees with febrile meningoencephalitis in Goma, Zaire, were studied. Gram-stained, cytocentrifuged smears were microscopically observed at magnifications of $\times 100$ and $\times 1,000$, each smear was plated onto Trypticase soy agar (BioMérieux, Marcyl'Etoile, France), chocolate agar (BioMérieux), and 5\% sheep blood Colombia agar (BioMérieux), and the preparations were incubated at $37^{\circ} \mathrm{C}$ for up to 10 days.

The culture requirements of the strain referred to below as isolate $\mathrm{MGB}^{\mathrm{T}}$ were further characterized by inoculating Trypticase soy agar, chocolate agar, 5\% sheep blood agar, and MacConkey agar (BioMérieux) plates and incubating the preparations for 10 days at both 30 and $37^{\circ} \mathrm{C}$. Phenotypic characterization of $\mathrm{MGB}^{\mathrm{T}}$ was based on Gram staining, a motility test, a respiratory (the strain was incubated at room temperature in Schäedler broth containing $0.2 \%$ agar), the catalase test, and the oxidase test (Diagnostic Pasteur, Marnes, France). Further biochemical analysis was performed by inoculating API 20NE and API 50CHE strips (BioMérieux) according to the manufacturer's instructions. The strips were incubated at $25^{\circ} \mathrm{C}$ for $24 \mathrm{~h}$. Carbon source utilization tests were performed by inoculating a Biotype-99 carbon source strip (BioMérieux) with Biotype 2 as-

* Corresponding author. Mailing address: Unité des Rickettsies, Faculté de Médecine, 27, Boulevard Jean Moulin, 13385 Marseille Cedex 05, France. Phone: 33.04.91.38.55.17. Fax: 33.04.91.83.03.90. similation medium (BioMérieux) (4) and incubating the preparation at $30^{\circ} \mathrm{C}$ Results were read on days 2 and 4 . The vigor of the strain was defined as the number of positive characteristics observed on the strips (3). Specific tests for Tween 80 hydrolysis, lecithinase production, and requirements for methionine, nitrate, and disaccharides were performed as described previously (18). Antibiotic susceptibility tests were performed by the disk diffusion method on MuellerHinton medium after $24 \mathrm{~h}$ of incubation at $37^{\circ} \mathrm{C}$ under aerobic conditions (24). The MICs of the following antibiotics were determined: ticarcillin (BeechamSévigné, Paris, France), ticarcillin-clavulanic acid (Beecham-Sévigné), piperacillin (Lederle, Rungis, France), mezlocillin (Bayer-Pharma, Sens, France), imipenem (MSD-Chibert, Paris, France), cephalothin (Lilly, Saint-Cloud, France), moxalactam (Lilly), cefoperazone (Pfizer, Orsay, France), cefotaxime (Roussel, Paris, France), ceftazidime (Glaxo, Paris, France), gentamicin (Schering-Plough, Levallois Perret, France), tobramycin (Lilly), amikacin (Bristol, Paris, France), netilmicin (Unicet, Levallois Perret, France), trimethoprim-sulfamethoxazole (Roche, Neuilly sur Seine, France), ciprofloxacin (Bayer Pharma), rifampin (Merell Dow, Neuilly sur Seine, France), fosfomycin (Clin Midy, Paris, France), and colimycin (Roger Bellon, Neuilly sur Seine, France).

Cellular fatty acids. Colonies of isolate $\mathrm{MGB}^{\mathrm{T}}$ grown on Trypticase soy agar (Becton Dickinson Microbiology, Meylan, France) at $28^{\circ} \mathrm{C}$ for 24 h were saponified, and cell wall fatty acid methyl esters were extracted and analyzed by gas chromatography as described previously (14). The profile was analyzed with MIDI software based on the profiles determined for 22 Stenotrophomonas maltophilia strains.

DNA-DNA hybridization. DNA was extracted from Trypticase soy agar-grown $\mathrm{MGB}^{\mathrm{T}}$ colonies and prototype strain colonies as described previously (5). Two micrograms of native DNA was labelled by nick translation with a nick translation kit (Boehringer Mannheim Biochemicals, Indianapolis, Ind.) by using tritium-labelled nucleotides (Amersham International, Amersham, England). Hybridization experiments in which the $\mathrm{S} 1$ nuclease-trichloroacetic acid method was used were performed as described previously (8). Experiments were performed twice to verify reproducibility. Both DNAs were labelled and hybridized with unlabelled DNA to avoid errors due to a possible difference in genome sizes.

$16 S$ ribosomal DNA (rDNA) sequencing. The DNA extracted from isolate $\mathrm{MGB}^{\mathrm{T}}$ was amplified by using PCR technology and universal primers fD1 and rp2 (23) (Eurogentec, Seraing, Belgium). PCR amplifications were performed in $50-\mu l$ reaction mixtures by adding each deoxynucleoside triphosphate to a concentration of $100 \mathrm{mM}$, each primer to a concentration of $0.2 \mu \mathrm{M}$, and $0.4 \mathrm{U}$ of Taq polymerase (Perkin-Elmer Cetus, Norwalk, Conn.). Amplifications were carried out with a Perkin-Elmer model 9600 thermal cycler by using 35 cycles consisting of denaturation at $90^{\circ} \mathrm{C}$ for $30 \mathrm{~s}$, primer annealing at $55^{\circ} \mathrm{C}$ for $30 \mathrm{~s}$, and extension at $72^{\circ} \mathrm{C}$ for $60 \mathrm{~s}$. The quality of the amplification was checked by ethidium bromide-stained $1 \%$ agarose gel electrophoresis. Each experiment included sterile water (no DNA) as a negative control and Escherichia coli DNA as a positive control. Amplified products were sequenced by using $5^{\prime}$-fluoresceinlabelled primers fD1, 800f (5'-ATT AGA TAC CCT GGT AG-3'), $1050 \mathrm{f}$ (5'TGT CGT CAG CTC GTG-3'), and RW1 (5'-TGA TGA CTT GAT GTC ATT CC-3') for direct sequencing, 5'-fluorescein-labelled primers $\mathrm{rp} 2,1050 \mathrm{r}$, and $800 \mathrm{r}$ for reverse sequencing (primers 1050r and 800r were reverse complementary to primers $1050 \mathrm{f}$ and $800 \mathrm{f}$, respectively), Tth DNA polymerase, and an AutoCycle sequencing kit (Pharmacia Biotech, Uppsala, Sweden) and were electrophoresed and analyzed with a model ALF DNA automatic sequencer (Pharmacia Biotech). To identify the $16 \mathrm{~S}$ rRNA sequences most similar to the $\mathrm{MGB}^{\mathrm{T}}$ sequence, searches of the EMBL and GenBank data libraries were performed by using the FASTA program (7). The sequence determined was then aligned with the se- 


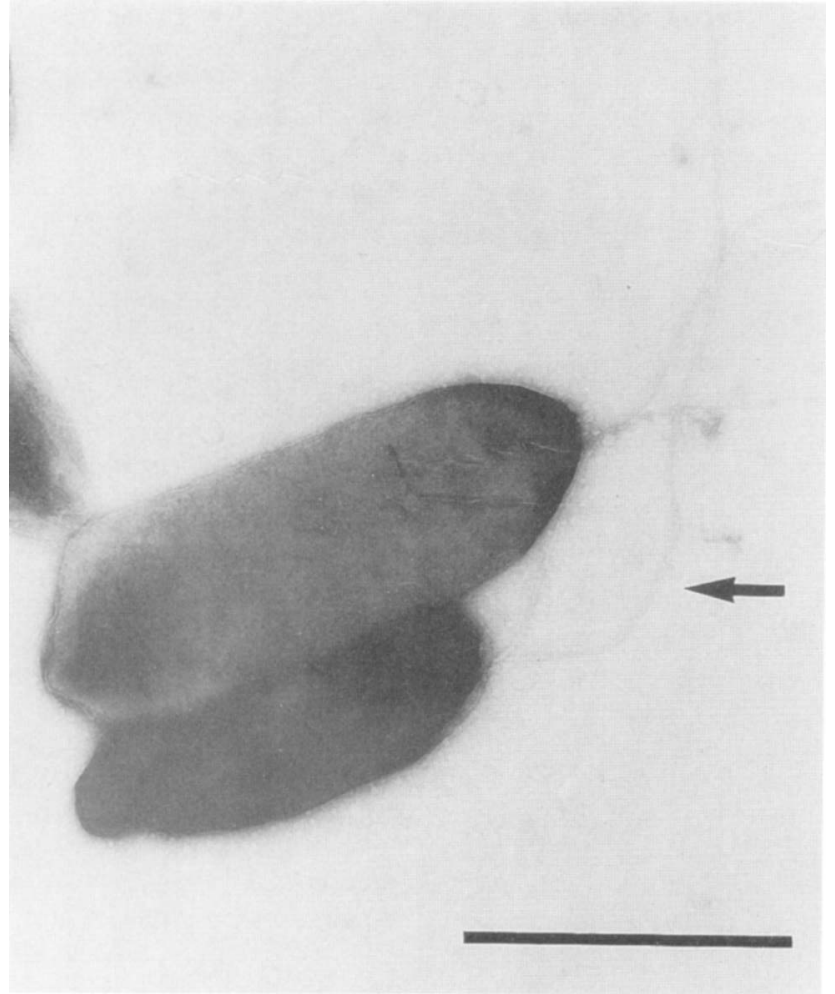

FIG. 1. Negatively stained electron micrograph of strain $\mathrm{MGB}^{\mathrm{T}}$, showing two polar flagella (arrow). The micrograph was taken with a JEOL, model 1,200 electron microscope. Magnification, $\times 33,200$. Bar $=1 \mu \mathrm{m}$.

quences of Stenotrophomonas maltophilia (GenBank accession number M59158), Pseudomonas aeruginosa (GenBank accession number X06684), Burkholderia cepacia (GenBank accession number M22518), Comamonas testosteroni (GenBank accession number M11224), and Cardiobacterium hominis (GenBank accession number M35014) through Bisance (6) by using the Clustal package (9).

Serology. Agar-grown isolate $\mathrm{MGB}^{\mathrm{T}}$ suspended in a $0.1 \%$ sodium azide solution was used as an antigen to test the CSF samples for the presence of immunoglobulin $\mathrm{G}$ (IgG), IgM, and IgA anti-MGB ${ }^{\mathrm{T}}$ antibodies. A microimmunofluorescence test performed by the standard procedure (15) was used.

Nucleotide sequence accession number. The nucleotide sequence of the $16 \mathrm{~S}$ rRNA gene of isolate $\mathrm{MGB}^{\mathrm{T}}$ has been deposited in the GenBank database under accession number U62646.

\section{RESULTS}

Isolation and culture. Of the seven CSF samples studied, three were sterile, one yielded Neisseria meningitidis, one yielded Streptococcus pneumoniae, and one yielded Bacillus cereus. A gram-negative rod (isolate $\mathrm{MGB}^{\mathrm{T}}$ ) was observed microscopically in the last sample, which was found to contain anti-HIV antibodies. Isolate $\mathrm{MGB}^{\mathrm{T}}$ formed faint fluorescent green colonies on Trypticase soy agar plates and grey colonies on sheep blood agar, chocolate agar, and MacConkey agar at both 30 and $37^{\circ} \mathrm{C}$. Growth was not accompanied by the ammonia odor typical of Stenotrophomonas maltophilia and was strictly aerobic.

Phenotypic characterization and antibiotic susceptibility. Isolate $\mathrm{MGB}^{\mathrm{T}}$ formed curved, Vibrio-like, gram-negative bacilli which were oxidase and indole negative and catalase positive. Motility was related to the presence of two polar flagella (Fig. 1 and Table 1). The isolate hydrolyzed Tween 80, gave a negative lecithinase reaction, and required methionine for growth. Growth was obtained when cellobiose, maltose, and lactose were used as carbon sources, but not when nitrate was used as a nitrogen source. The isolate formed acid from glucose, fructose, mannose, sucrose, lactose, and maltose and hydrolyzed gelatin, esculin, and ortho-nitrophenyl- $\beta$-D-galactopyranoside. Lysine decarboxylase activity was present (Table 1). In the carbon source study, isolate MGB ${ }^{\mathrm{T}}$ yielded the same auxanogram as the Stenotrophomonas maltophilia type strain except for the assimilation of cis-aconitate, which was positive for isolate $\mathrm{MGB}^{\mathrm{T}}$ but not for the Stenotrophomonas maltophilia type strain. The cell wall fatty acid pattern of $\mathrm{MGB}^{\mathrm{T}}$ was similar to that reported for Stenotrophomonas maltophilia (25) and identical to the identifying profile determined by an analysis of 22 strains by the MIDI software; i.e., $\mathrm{C}_{15}$ fatty acids represented $45 \%$ of the total fatty acids and $\mathrm{C}_{16}$ fatty acids represented $10 \%\left(\mathrm{C}_{16: 0}\right.$ iso, $\left.2.87 \%\right)$ of the total fatty acids. Isolate $\mathrm{MGB}^{\mathrm{T}}$ was susceptible to netilmicin (MIC, $4 \mathrm{mg} / \mathrm{liter}$ ), ciprofloxacin (MIC, $<1 \mathrm{mg} /$ liter), trimethoprim-sulfamethoxazole (MIC, $1 \mathrm{mg} /$ liter), and colimycin (MIC, $<2 \mathrm{mg} / \mathrm{liter}$ ). It was resistant to all other antibiotics tested, including ticarcillinclavulanic acid, cefoperazone, and imipenem (Table 2).

Genotypic identification. A total of 1,451 positions of the 16S rRNA gene of isolate $\mathrm{MGB}^{\mathrm{T}}$ were sequenced. The Stenotrophomonas maltophilia 16S rDNA sequence, however, included 74 undetermined positions, and when these were removed from the analysis, 24 of the 1,377 paired positions of the isolate $\mathrm{MGB}^{\mathrm{T}} 16 \mathrm{~S}$ rDNA sequence and the Stenotrophomonas maltophilia 16S rDNA sequence differed, resulting in a level of similarity of $98.3 \%$. The $\mathrm{MGB}^{\mathrm{T}}$ sequence exhibited of $92.9 \%$ similarity with the Stenotrophomonas (Xanthomonas) maltophilia sequence, $83.3 \%$ similarity with the Pseudomonas aerugi-

TABLE 1. Characteristics of strain $\mathrm{MGB}^{\mathrm{T}}$

\begin{tabular}{|c|c|c|c|}
\hline Characteristic & 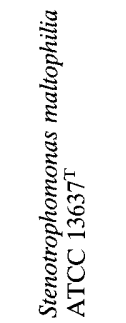 & 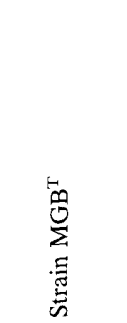 & 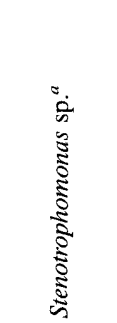 \\
\hline Gram stain reaction & Negative & Negative & Negative \\
\hline Motility & $+b$ & + & + \\
\hline No. of flagella & $>1$ & 2 & NR \\
\hline Oxidase & - & - & + \\
\hline Catalase & + & + & NR \\
\hline \multicolumn{4}{|l|}{ Growth requirements } \\
\hline Methionine & - & - & NR \\
\hline Nitrate & - & - & NR \\
\hline Cellobiose & + & + & NR \\
\hline Maltose & + & + & NR \\
\hline Lactose & + & + & NR \\
\hline Indole production & - & - & NR \\
\hline Nitrate reduction & - & - & + \\
\hline Acid produced from sucrose & + & + & - \\
\hline Acid produced from lactose & + & + & - \\
\hline Lactico dehydrogenase & + & + & - \\
\hline Lecithinase production & - & - & NR \\
\hline Gelatin hydrolysis & + & + & + \\
\hline Tween 80 hydrolysis & + & + & NR \\
\hline $\begin{array}{l}\text { \% 16S rRNA homology with } \\
\text { ATCC } 13637^{\mathrm{T}}\end{array}$ & 100 & 98.7 & 94 \\
\hline $\begin{array}{l}\% \text { DNA hybridization with } \\
\text { ATCC } 13637^{\mathrm{T}}\end{array}$ & 100 & 35 & NR \\
\hline
\end{tabular}

${ }^{a}$ New Stenotrophomonas species described by Bernard et al. (2).

${ }^{b}+$, positive; - , negative; NR, not reported. 
TABLE 2. MICs of selected antibiotics against isolate $\mathrm{MGB}^{\mathrm{T}}$ as determined by the disk diffusion method

\begin{tabular}{|c|c|}
\hline Antibiotic & $\begin{array}{c}\text { MIC } \\
\text { (mg/liter) }\end{array}$ \\
\hline Ticarcillin ....... & 256 \\
\hline 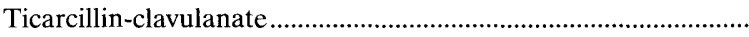 & 256 \\
\hline Piperacillin & 256 \\
\hline Mezlocillin & 256 \\
\hline Imipenem ....... & 32 \\
\hline Cephalothin ..... & 128 \\
\hline Moxalactam...... & 256 \\
\hline Cefoperazone & $\ldots \quad 256$ \\
\hline Cefotaxime & $\ldots 1,024$ \\
\hline Ceftazidime.... & $\ldots 1,024$ \\
\hline Gentamicin & ... 32 \\
\hline Tobramycin & 32 \\
\hline Amikacin & 32 \\
\hline Netilmicin & 4 \\
\hline Trimethoprim-sulfamethoxazole & 1 \\
\hline 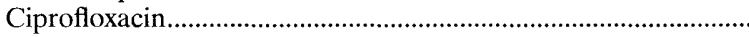 & $<1$ \\
\hline 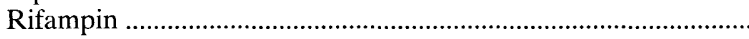 & 32 \\
\hline (n) & $\ldots>32$ \\
\hline Colimyctin ... & $\ldots<2$ \\
\hline
\end{tabular}

nosa sequence, $81.8 \%$ similarity with the Burkholderia cepacia sequence, and $81.5 \%$ similarity with the Comamonas testosteroni sequence. DNA-DNA hybridization revealed 35\% similarity between isolate $\mathrm{MGB}^{\mathrm{T}}$ and the Stenotrophomonas maltophilia type strain.

Serology. Five of the seven CSF samples tested were nonreactive, one sample exhibited a 1:10 IgG titer, and the sample which yielded isolate $\mathrm{MGB}^{\mathrm{T}}$ exhibited titers of $1: 10$ for IgG, 1:8 for IgM, and 1:8 for IgA.

\section{DISCUSSION}

The role of isolate $\mathrm{MGB}^{\mathrm{T}}$ in meningoencephalitis in a Rwandan refugee was determined by direct observation in and isolation from a CSF sample from one patient, by the vigor of the isolate determined after biochemical characterization, which indicated that the source of the isolate was clinical rather than environmental (3), and by the demonstration of specific antibodies in the CSF sample from which isolate $\mathrm{MGB}^{\mathrm{T}}$ was recovered. Although the phenotypic characteristics of isolate $\mathrm{MGB}^{\mathrm{T}}$ suggested that it was a Stenotrophomonas species, its isolation from the CSF of a patient suffering from primary meningoencephalitis and not nosocomial meningoencephalitis, its unusual vibrio-like morphology, and its broadspectrum antibiotic resistance, which is unusual for a community-acquired strain, led us to question its relationship to the only previously recognized member of the genus Stenotrophomonas, Stenotrophomonas maltophilia, and to use a polyphasic approach for its identification. The $98.3 \%$ similarity of $16 \mathrm{~S}$ rDNA sequences confirmed that there is a specific relatedness between isolate $\mathrm{MGB}^{\mathrm{T}}$ and Stenotrophomonas maltophilia, but suggested that some divergence between the two organisms had occurred. DNA-DNA hybridization remains the ultimate criterion for determination of a bacterial species (22). At present, there is no consensus regarding the determination of bacterial taxa based on 16S rRNA gene sequencing, although it has been noted that strains sharing less than $97 \%$ similarity usually do not belong to the same species (17). A DNA hybridization value of $35 \%$ clearly indicates that strain $\mathrm{MGB}^{\mathrm{T}}$ is distinct from Stenotrophomonas maltophilia. The genus Stenotrophomonas was recently created for Stenotrophomonas mal- tophilia (16), a species initially assigned to the genus Pseudomonas $(10,11)$ and then to the genus Xanthomonas (19). The latter classification was considered controversial, especially because Xanthomonas and Stenotrophomonas spp. differ in basic properties that would require redefinition of the genus Xanthomonas to accommodate Xanthomonas maltophilia (20) and because the genus Xanthomonas previously included only plant pathogens (21).

Stenotrophomonas maltophilia has been shown to be responsible for nosocomial infections in patients exposed to large inocula or patients with impaired host defenses (12) and was implicated in catheter-related bacteremia and septicemia, urinary tract infections, respiratory tract infections, meningitis, serious wound infections, mastoiditis, epididymitis, conjunctivitis, and endocarditis (26). Recently, two groups of Stenotrophomonas maltophilia-related strains have been identified from environmental and clinical (immunocompromised patient) sources (2). The phenotypic characteristics of these isolates are different from those of our isolate (Table 1). Apart from primary pneumonia, Stenotrophomonas maltophilia has never been implicated in primary, nonnosocomial infections in humans. Isolate $\mathrm{MGB}^{\mathrm{T}}$ is not nosocomial in origin, but was isolated from an HIV-infected patient. $\mathrm{MGB}^{\mathrm{T}}$ is the most naturally resistant gram-negative bacterium isolated from a community-acquired infection. Antibiotics are not widely available in Central Africa, and the refugees in the area had received only chloramphenicol. Selection of a resistant strain is therefore very unlikely. Stenotrophomonas maltophilia is also highly resistant to antibiotics, but it is regularly susceptible to trimethoprim-sulfamethoxazole and some newer quinolones (13) and irregularly susceptible to ticarcillin-clavulanic acid, moxalactam, cefoperazone, and ciprofloxacin (12). Trimethoprim-sulfamethoxazole is the treatment of choice. Isolate $\mathrm{MGB}^{\mathrm{T}}$ was even more antibiotic resistant than Stenotrophomonas maltophilia, since it was susceptible only to netilmicin, ciprofloxacin, trimethoprim-sulfamethoxazole, and colimycin. The recently reported Stenotrophomonas maltophilia-related isolates discussed above, however, were not multiresistant (2). A comprehensive polyphasic review of the characteristics of isolate $\mathrm{MGB}^{\mathrm{T}}$ suggests that this strain belongs to a new Stenotrophomonas species. The name Stenotrophomonas africana is proposed for this new species.

Description of Stenotrophomonas africana. Stenotrophomonas africana (a. fri. ca' na. L. adj. africana, from Africa, the continent where the organism was first isolated) is a curved, gram-negative, nonsporulating bacterium whose cells are typically $0.5 \mu \mathrm{m}$ wide and $1.5 \mu \mathrm{m}$ long. It is motile by means of two polar flagella. Tests for oxidase and indole are negative, but catalase is present. It forms grey to green colonies lacking an ammonia odor. The biochemical pattern is identical to that of Stenotrophomonas maltophilia, except for the lack of assimilation of cis-aconitate. Antibiotic susceptibility is restricted to netilmicin, ciprofloxacin, trimethoprim-sulfamethoxazole and colimycin. A total of 24 of 1,377 16S rDNA base positions determined are different from those of Stenotrophomonas maltophilia, and the level of DNA hybridization between the species is $35 \%$. Stenotrophomonas africana has been isolated once from the CSF of an African patient who tested positive for HIV antibodies and exhibited primary meningoencephalitis. The type strain of Stenotrophomonas africana is strain MGB, which has been deposited in the Collection de l'Institut Pasteur, Paris, France, as strain 10-48-54.

\section{ACKNOWLEDGMENT}

This work was supported by Programme Hospitalier de Recherche Clinique, Assistance Publique à Marseille, 1993. 


\section{REFERENCES}

1. Anonymous. 1994. Epidemic typhus risk in Rwandan refugee camps. WHO Weekly Epidemiol. Rec. 34:259.

2. Bernard, K., S. Tessier, C. Munro, M. Oughton, and S. Tyler. 1996. Characterization of two clusters of previously undescribed gram-negative bacteria, possibly genus Stenotrophomonas species nova, abstr. C407, p. 73. In Abstracts of the 96th General Meeting of the American Society for Microbiology 1996. American Society for Microbiology, Washington, D.C.

3. Bollet, C., and P. De Micco. 1992. Taxonomic methods, p. 179-200. In J Ledeberg (ed.), Encyclopedia of microbiology. Academic Press, New York, N.Y.

4. Bouvet, O. M. M., P. A. D. Grimont, C. Richard, E. Aldova, O. Hausner, and M. Gabrhelova. 1985. Budvicia aquatica gen. nov., sp. nov.: a hydrogen sulfide-producing member of the Enterobacteriaceae. Int. J. Syst. Bacteriol. 35:60-64.

5. Brenner, D. J., A. McWhorter, J. K. Leete-Knudson, and A. G. Steigerwalt. 1982. Escherichia vulneris: a new species of Enterobacteriaceae associated with human wounds. J. Clin. Microbiol. 15:1133-1140.

6. Dessen, P., C. Fondrat, C. Valencien, and C. Mugnier, 1990. Bisance: French service for access to biomolecular sequence databases. Cabios 6:355356.

7. Devereux, J., P. Haeberli, and D. Smithies. 1984. A comprehensive set of sequence analysis programs for the VAX. Nucleic Acids Res. 12:387-395.

8. Grimont, P. A. D., M. Y. Popoff, F. Grimont, C. Coynault, and M. Lemelin 1980. Reproductibility and correlation study of three deoxyribonucleic acid hybridization procedures. Curr. Microbiol. 4:325-330.

9. Higgins, D. G., and P. M. Sharp. 1988. CLUSTAL: a package for performing multiple sequence alignment on a microcomputer. Gene 73:237-244.

10. Hugh, R. 1981. Pseudomonas maltophilia sp. nov., nom. rev. Int. J. Syst. Bacteriol. 31:195.

11. Hugh, R., and E. Ryschenkow. 1961. Pseudomonas maltophilia, an Alcaligenes-like species. J. Gen. Microbiol. 26:123-132.

12. Khardori, N., L. Elting, E. Wong, B. Schable, and G. P. Bodey. 1990. Nosocomial infections due to Xanthomonas maltophilia (Pseudomonas maltophilia) in patients with cancer. Rev. Infect. Dis. 12:997-1003.

13. Khardori, N., A. Reuben, B. Rosenbaum, K. Rolston, and G. P. Bodey. 1990 In vitro susceptibility of Xanthomonas (Pseudomonas) maltophilia to newer antimicrobial agents. Antimicrob. Agents Chemother. 34:1609-1610.

14. Miller, L., and T. Berger. 1985. Bacterial identification by gas chromatog raphy of whole cell fatty acids. Hewlett-Packard application note 228-41. Hewlett-Packard, Avondale, $\mathrm{Pa}$.

15. Nakamura, R. M., and B. A. Robbins. 1992. Fluorescence immunoassays, p.
10-17. In N. R. Rose, E. Conway de Macario, J. L. Fahey, H. Friedman, and G. M. Penn (ed.). Manual of clinical laboratory immunology, 4th ed. American Society for Microbiology, Washington D.C.

16. Palleroni, N. J., and J. F. Bradbury. 1993. Stenotrophomonas, a new bacterial genus for Xanthomonas maltophilia (Hugh 1980) Swings et al. Int. J. Syst. Bacteriol. 43:606-609.

17. Stackebrandt, E., and B. M. Goebel. 1994. Taxonomic note: a place for DNA-DNA reassociation and $16 \mathrm{~S}$ rRNA sequence ana'ysis in the present species definition in bacteriology. Int. J. Syst. Bacteriol. 44:846-849.

18. Stanier, R. Y., N. J. Palleroni, and M. Doudoroff. 1966. The aerobic pseudomonads: a taxonomic study. J. Gen. Microbiol. 43:159-271.

19. Swings, J., P. De Vos, M. Van den Mooter, and J. De Ley. 1983. Transfer of Pseudomonas maltophilia Hugh 1981 to the genus Xanthomonas as Xanthomonas maltophilia (Hugh 1981) comb. nov. Int. J. Syst. Bacteriol. 33:409413.

20. Van Zyl, E., and P. L. Steyn. 1992. Reinterpretation of the taxonomic position of Xanthomonas maltophilia and taxonomic criteria in this genus. Request for an opinion. Int. J. Syst. Bacteriol. 42:193-198.

21. Vauterin, L., J. Swings, K. Kersters, M. Gillis, W. Mew, N. Schroth, N. J. Palleroni, D. C. Hildebrand, D. E. Stead, E. L. Civerolo, A. C. Hayward, H. Maraître, R. E. Stall, A. K. Vidaver, and J. F. Bradbury. 1990. Towards and improved taxonomy of Xanthomonas. Int. J. Syst. Bacteriol. 40:312-316.

22. Wayne, L. G., D. J. Brenner, R. R. Colwell, P. A. D. Grimont, O. Kandler, M. I. Krichevsky, L. H. Moore, W. E. C. Moore, R. G. E. Murray, E Stackebrandt, M. P. Starr, and H. G. Trüper. 1987. Report of the Ad Hoc Committee on Reconciliation of Approaches to Bacterial Systematics. Int. J. Syst. Bacteriol. 37:463-464.

23. Weisburg, W. G., S. M. Barns, D. A. Pelletier, and D. J. Lane. 1991. 16S ribosomal DNA amplification for phylogenetic study. J. Bacteriol. 173:697703.

24. Woods, G. L., and J. A. Washington. 1995. Antimicrobial susceptibility tests: dilution and disk diffusion methods, p. 1327-1341. In P. R. Murray, E. J. Baron, M. A. Pfaller, F. C. Tenover, and R. H. Yolken (ed.), Manual of clinical microbiology, 6th ed. American Society for Microbiology, Washington, D.C.

25. Yang, P., L. Vauterin, M. Vancanneyt, J. Swings, and K. Kersters. 1993 Application of fatty acid methyl esters for the taxonomic analysis of the genus Xanthomonas. Syst. Appl. Microbiol. 16:47-71.

26. Zuravleff, J. J., and V. L. Yu. 1982. Infections caused by Pseudomonas maltophilia with emphasis on bacteremia: case reports and a review of the literature. Rev. Infect. Dis. 4:1236-1246. 